\title{
(2) OPEN ACCESS \\ Recovery from work: testing the effects of chronic internal and external workload on health and well-being
}

\author{
Mark Cropley (10,1 Leif W Rydstedt (10, ${ }^{2}$ David Andersen ${ }^{2}$
}

\begin{abstract}
- Additional material is published online only. To view please visit the journal online (http://dx.doi.org/10.1136/ jech-2019-213367)

${ }^{1}$ School of Psychology, University of Surrey, Guildford, UK ${ }^{2}$ Department of Psychology, Norwegian Inland University of Applied Sciences, HHS Elverum, Norway
\end{abstract}

\section{Correspondence to}

Leif W Rydstedt, Department of Psychology, Norwegian Inland University of Applied Sciences, HHS Elverum, Postboks 4002418 Elverum, Norway; Leif.Rydstedt@inn.no

Received 14 October 2019 Revised 21 December 2019 Accepted 12 June 2020
Check for updates

(C) Author(s) (or their employer(s)) 2020. Re-use permitted under CC BY-NC. No commercial re-use. See rights and permissions. Published by BMJ.

\section{To cite: Cropley M,} Rydstedt LW, Andersen D. J Epidemiol Community Health 2020;74:919-924.

\begin{abstract}
Background The aim of this study was to examine the effects of reduced recovery opportunities on health, associated with chronic internal workload (ie, during work) and external workload (ie, following work).
\end{abstract}

Methods Data from two consecutive surveys (2013 and 2016) from the Norwegian Living Conditions Survey on Work Environment were used. To assess a dose-response association between workload and health, self-reported ratings of internal workload (ie, having too much to do and skipping lunch breaks during work) and external workload (ie, using mobile technology for work-related issues during leisure time) over the two time periods were divided into tertile groups representing low, medium and high workload. Anxiety, depression, physiological and psychological fatigue and sleep were assessed as outcome symptoms.

Results Chronic medium levels of internal workload were associated with psychological fatigue $(\mathrm{OR}=2.84$, $95 \% \mathrm{Cl} 1.75$ to 4.62$)$ and physical fatigue $(\mathrm{OR}=1.85$, $95 \% \mathrm{Cl} 1.31$ to 2.63$)$, and high internal workload was associated with psychological fatigue $(\mathrm{OR}=7.24,95 \% \mathrm{Cl}$ 4.59 to 11.40$)$, physical fatigue $(\mathrm{OR}=4.23,95 \% \mathrm{Cl} 3.06$ to 5.83$)$ and sleep problems (OR=1.81, 95\% Cl 1.07 to 3.05). Chronic external high workload was only associated with psychological fatigue $(\mathrm{OR}=1.67,95 \% \mathrm{Cl}$ 1.26 to 2.22 ) and with physical fatigue problems $(\mathrm{OR}=1.47,95 \% \mathrm{Cl}, 1.09-1.98)$ when the data were adjusted for age, gender, education level, job autonomy and occupational status.

Conclusions This study emphasises that individuals who chronically experience high workload are at an increased risk for reporting psychological and physical fatigue, and sleep problems.

\section{INTRODUCTION}

The need for recovery from work in relation to health and well-being has been emphasised in several psychological models. According to Hobfoll's ${ }^{1}$ Conservation of Resources (COR) model, individuals have an innate drive that motivates them to 'create, foster and conceive' personal resources. Key resources are those that help to maintain survival, self-esteem and well-being. Work demands are thought to be particularly resource consuming. ${ }^{2}$ In terms of the Effort-Recovery model, Meijman and Mulder $^{3}$ argue that during demanding work individuals expend psychological and physical resources in order to complete task requirements. Following demanding work, such resources are depleted, and restored only after a period of rest. Failure to adequately restore depleted resources results in a greater need for recovery, and fatigue, and can lead to the development of health problems. ${ }^{34}$

Both the COR and the Effort-Recovery models are quite prescriptive, suggesting that recovery naturally occurs in the absence of work. Others have argued that recovery should be conceptualised as a dynamic construct relating to changes in the psycho-physiological state of the person. ${ }^{5}$ In this perspective, recovery is understood as an active process, and 'recovery' can never be fully achieved as there is no actual point when you can identify when someone is recovered. ${ }^{5}$ Therefore, it is argued that research should focus on recovery as a regulation process. ${ }^{5}$ Temporarily disengaging from work activities (mentally and physically) throughout the working day may help to rebuild resources, thus aiding the recovery process. ${ }^{6}$

It is possible to think of recovery in terms of behaviours that can occur during working hours ('internal recovery') and recovery that takes place outside of work during leisure time ('external recovery'). ${ }^{6}$ Internal recovery can be obtained through imposed or unscheduled rest breaks, which help to prevent the accumulation of workload and fatigue that builds up during the day. Research has demonstrated that taking small recovery breaks in the afternoon can boost work engagement ${ }^{7}$ and regular breaks during the day help people keep motivated and energised. ${ }^{8} 9$ Furthermore, regular recovery breaks can decrease the risk of injuries at work. ${ }^{10}$ Taking regular breaks throughout the working day has also been associated with increased job performance. ${ }^{11}$

Arguably, the most important internal recovery takes place during lunch breaks. ${ }^{12}$ Taking lunch breaks has been associated with increased energy levels at work, ${ }^{13}$ reduced fatigue ${ }^{14}$ and positive affect. ${ }^{11}$ The positive effects on health, well-being and performance by taking a break seem to be moderated by levels of autonomy. ${ }^{14}$ While the available evidence suggests that work breaks including lunch breaks are generally associated with greater health, well-being ${ }^{15}$ and work performance issues, ${ }^{11} 1617$ this conclusion is based on a small number of studies and there is a clear lack of longitudinal research in this area.

Mobile technology has revolutionised the way people work. By the use of smartphone and tablets, it has become relatively easy over recent years to stay connected to work and to work pretty much anywhere. ${ }^{18}$ This enables workers to be contacted outside of work and to conduct work outside their contractual hours, which has generally been thought to impede recovery as it 
places similar demands on the psycho-physiological systems that were activated during work. ${ }^{2}{ }^{5}$ Occasionally working without a break and outside scheduled hours is unlikely to have a long-term impact on health, but habitually working during one's leisure time in order to fulfil work demands is likely to increase the risk of chronic fatigue, exhaustion and other health issues. ${ }^{19}$

Geurts and Sonnetag ${ }^{6}$ argue that both internal and external recovery are necessary prerequisites for maintaining health and that 'incomplete recovery is an important pathway for chronic health impairment'. Although both internal and external recovery have been identified as being important mechanisms underlying health impairment, it appears that the majority of research has focused on external recovery, and there is a clear lack of knowledge concerning the effects of internal recovery on health. ${ }^{20}{ }^{21}$ Indeed, researchers have commented on the particular lack of empirical evidence surrounding the role of lunch breaks as an internal recovery aid. ${ }^{20}$

In summary, recovering from the demands of work is vital for health and well-being. The aim of the present study was to examine the effects of internal and external workload that impedes recovery, on health, over time (chronically), by using data from the longitudinal Norwegian Living Conditions Survey on Work Environment (2013-2016). ${ }^{\mathrm{I}}$ This nationwide survey is representative of Norwegian workers, and one of the strengths of the survey is that the same workers are followed over time, thus allowing the examination of variables within the same individuals over time. We examined the effects of chronic internal workload, defined as having too much work to do and skipping breaks during the working day, and chronic external workload, defined as using technology for work purposes during leisure time, on health and well-being. Five distress symptom outcomes were examined: anxiety, depression, physical fatigue, psychological fatigue and sleep problems.

\section{METHOD}

\section{Study population}

The data were provided by Statistics Norway's (SSB) Levekårundersøkelsen om Arbeidsmiljø 2013 and 2016 (The Living Conditions Survey) on Working Conditions and Working Environment. ${ }^{\text {II }}$ This survey is conducted approximately every 3 years, and the data are representative of the Norwegian population. Data were collected through telephone interviews in the period from April 2013 to January 2014, for the 2013 survey, and in the period from April 2015 to January 2016 for the 2016 survey. The 2013 survey ${ }^{\text {III }}$ contained 10875 individuals; however, by including only those reporting to work 25 hours or more, and between the ages of 17-67 years, the sample was reduced to 4758 individuals. Of these 4758 individuals, 3186 (70\%) responded to the follow-up survey in 2016. Due to missing/ incomplete data, the final sample size for the internal workload group was $n=1715$, and $n=1760$ for the external workload group. The sample characteristics are reported in table 1.

\section{Measures}

\section{Internal and external workload}

Internal workload was assessed using the following three

\footnotetext{
'Data for the 2016 was released in 2018.

"The data were provided by Statistics Norway, and prepared and made available by NSD—Norwegian Centre for Research Data. Neither Statistics Norway nor NSD are responsible for the analysis/interpretation of the data presented here.

II'https://www.ssb.no/arbeid-og-lonn/artikler-og-publikasjoner/_attachment/ 212821?_ts=14a6251f8f8
}

Table 1 Demographic characteristics (mean, SD or observations) and the distress variables (mean, SD) for internal workload $(n=1715)$ and external workload $(n=1760)$

\begin{tabular}{|c|c|c|c|c|}
\hline & \multicolumn{2}{|c|}{$\begin{array}{l}\text { Internal workload } \\
n=1715\end{array}$} & \multicolumn{2}{|c|}{$\begin{array}{l}\text { External workload } \\
n=1760\end{array}$} \\
\hline & $\begin{array}{l}\text { Mean or } \\
\text { number }\end{array}$ & $\begin{array}{l}\text { SD or } \\
(\%)\end{array}$ & $\begin{array}{l}\text { Mean or } \\
\text { number }\end{array}$ & $\begin{array}{l}\text { SD or } \\
(\%)\end{array}$ \\
\hline Age (in years) & 43.47 & 10.70 & 44.06 & 10.39 \\
\hline \multicolumn{5}{|l|}{ Gender } \\
\hline Men & 963 & $(56.2 \%)$ & 962 & $(54.7 \%)$ \\
\hline Women & 752 & $(43.8 \%)$ & 798 & $(45.3 \%)$ \\
\hline \multicolumn{5}{|l|}{ Education level* } \\
\hline 0 & 1 & 1 & 1 & 1 \\
\hline $1-3$ & 703 & 41 & 714 & 40.6 \\
\hline $4-5$ & 722 & 42.1 & 747 & 42.5 \\
\hline $6-8$ & 289 & 16.8 & 298 & 16.8 \\
\hline Job autonomy & 2.35 & 0.76 & 2.32 & 0.78 \\
\hline \multicolumn{5}{|l|}{$\begin{array}{l}\text { Occupational } \\
\text { positiont }\end{array}$} \\
\hline 1 & 236 & 13.8 & 252 & 14.3 \\
\hline 2 & 678 & 39.5 & 697 & 39.6 \\
\hline 3 & 276 & 16.1 & 285 & 16.2 \\
\hline 4 & 89 & 5.2 & 102 & 5.8 \\
\hline 5 & 167 & 9.7 & 171 & 9.7 \\
\hline 6 & 23 & 1.3 & 20 & 1.1 \\
\hline 7 & 135 & 7.9 & 128 & 7.3 \\
\hline 8 & 73 & 4.3 & 69 & 3.9 \\
\hline 9 & 17 & 1.0 & 21 & 1.2 \\
\hline Anxiety & 3.86 & 0.42 & 3.87 & 0.15 \\
\hline Depression & 3.88 & 0.39 & 3.90 & 0.36 \\
\hline Psychological fatigue & 4.25 & 1.12 & 4.30 & 1.08 \\
\hline Physical fatigue & 3.90 & 1.31 & 3.96 & 1.27 \\
\hline Sleep problems & 3.66 & 0.67 & 3.68 & 0.654 \\
\hline
\end{tabular}

items: (1) Do you have so much to do that you work skip lunch, (2) How often is it necessary to work at a high pace? and (3) How often do you have too much to do? Items were rated on a 5 -point scale with $5=$ very often or always, $4=$ somewhat often, $3=$ occasionally, $2=$ rarely and $1=$ very rarely or never. The internal consistency (Cronbach's $\alpha$ ) of this factor was 0.71 (2013) and 0.70 (2016). External recovery was assessed using the following three items: (1) How often are you contacted outside of work time? (2) How often do you read and answer emails outside of working hours? and (3) How often do you keep updated on electronic information for work outside of working hours (eg, blogs, social media, etc). Internal workload items are adapted from the Job Content Questionnaire. ${ }^{22}$ The internal consistency (Cronbach's $\alpha$ ) of this factor was 0.74 (2013) and 0.72 (2016).

\section{Distress symptoms}

Experience of distress was assessed in 2016, using the following symptoms: anxiety, depression, physical fatigue, psychological 
fatigue and sleep problems. Anxiety, depression and sleep items were rated on a 4-point scale from $1=$ not bothered, $2=$ little bothered, $3=$ quite bothered and $4=$ very bothered over the previous month. Ratings were recoded into dummy variables; values 1 through 2 coded as low, and 3 through 4 being high for each symptom. Physical and psychological fatigue were rated on a 5 -point scale from $1=$ daily, $2=$ sometimes per-week, $3=$ once a week, $4=$ sometime per-month and $5=$ never/almost never. Similar variables have previously been used as distress symptoms in several other studies that have examined the consequences of insufficient external recovery. ${ }^{23-26}$ The prevalence and percentages of the distress symptoms are presented in online supplemen tary tables $\mathrm{S} 1$ and $\mathrm{S} 2$.

\section{Covariates}

\section{Education level}

Education level was classified by the Norwegian standard (0-8) grouping for education level, ${ }^{27}$ where $0=$ no education, $1-3=$ mandatory education, $4-5=$ further vocational education and $6-8=$ higher education.

\section{Occupational classification}

Occupational classification was based on the Norwegian standard for occupational classification ${ }^{28}$ where $1=$ managerial positions, $2=$ academic/professional positions (requiring higher education), $3=$ professions requiring college level of education, $4=$ office/administrative profession, $5=$ sales and service professions, $6=$ farming, fishing, etc, $7=$ skilled crafts, $8=$ machine operators and transport workers, and $9=$ unskilled professions.

\section{Job autonomy}

Levels of autonomy at work were assessed using the mean of the following three items: (1) to what extent can you decide how to work, (2) to what extent can you decide your work pace and (3) to what extent can you influence decisions that are important to you at work. Items were rated on a 5 -point scale with $5=$ a very high degree, $4=a$ high degree, $3=$ to some degree, $2=$ to a small degree and $1=a$ very small degree. The internal consistency (Cronbach's $\alpha$ ) of this factor was 0.70 (2013) and 0.72 (2016). Internal workload and job autonomy items are adapted from the Job Content Questionnaire. ${ }^{22}$

\section{Data analysis}

To examine the association between workload and distress symptoms (anxiety, depression, physical fatigue, psychological fatigue and sleep problems) at 2016, ratings of internal and external workload made at 2013 and 2016 were divided into tertiles (low, medium, high, using the 2013 cut-offs). Thus, three groups were formed representing individuals who chronically reported either low, medium and high workload (internal or external) at 2013 and 2016. Individuals who changed exposure group, for example, from high to low, were omitted from the analysis. This resulted in a loss of 1471 individuals for internal workload and 1426 individuals for external workload. For each set of analysis, the low workload group was used as the comparison against the medium and high workload groups. For each symptom, crude ORs were initially calculated using logistic regression analysis, and then age, gender, education level, job autonomy and occupational position (entered as a ranked categorical variable broken into dummies) were included as covariates. For completeness, we also report a separate set of analysis (online supplementary tables S3 and S4) where we report the association between the average measure of workload between 2013 and 2016, and distress symptoms. This resulted in an increased number of participants available for analysis (internal workload $n=2989$, external workload $n=3186$ ).

\section{RESULTS}

Table 1 reports the demographic characteristics and the mean and SD of the study variables. Table 2 summarises the crude and adjusted ORs for internal recovery. As can be seen in table 2, medium and high workload exposure increased the risk of reporting psychological and physical fatigue, with the risk greater in the group reporting high workload. Specifically, for psychological fatigue, the ORs for the medium exposure group was 2.84 , and 7.24 for the high exposure, and 1.85 and 4.23 , respectively, for physical fatigue. The OR for sleep problems was 1.81 for the high internal workload group. After adjustment for age, gender, education level, job autonomy and occupational position, the ORs decreased slightly, but the overall pattern of the results remained comparable.

Online supplementary table S3 summarises the crude and adjusted ORs for internal workload based on the data from the averaged measure of workload between 2013 and 2016, and distress symptoms. The ORs for the medium exposure group was 1.36 for anxiety, 2.43 for psychological fatigue and 1.76 for physical fatigue. For the high exposure group, the ORs was 1.47 for anxiety, 4.56 for psychological fatigue, 3.22 for physical fatigue and 1.66 for sleep problems. After adjusting for age, gender, education level, job autonomy and occupational position, the ORs for the medium exposure group was 2.14 for psychological fatigue and 1.84 for physical fatigue; the ORs for the high exposure group was 1.42 for anxiety, 3.80 for psychological fatigue, 3.78 for physical fatigue and 1.57 for sleep problems. After adjusting for age, gender, education level, job autonomy, occupational position and distress symptoms reported at 2013, psychological fatigue (ORs $=1.85$ and 3.04) and physical fatigue were $(\mathrm{ORs}=1.53$ and 2.83$)$ were the only distress

Table 2 Crude and adjusted ORs (95\% Cls) of internal workload group (low, medium, high) (2013-2016) on physical and psychological well-being

\begin{tabular}{|c|c|c|c|c|c|}
\hline & Anxiety & Depression & $\begin{array}{l}\text { Psychological } \\
\text { fatigue }\end{array}$ & $\begin{array}{l}\text { Physical } \\
\text { fatigue }\end{array}$ & $\begin{array}{l}\text { Sleep } \\
\text { problems }\end{array}$ \\
\hline \multicolumn{6}{|c|}{ Crude OR (95\% Cl) } \\
\hline Low & 1 & 1 & 1 & 1 & 1 \\
\hline Medium & $\begin{array}{l}0.92 \\
(0.59-1.43)\end{array}$ & $\begin{array}{l}1.45 \\
(0.87-2.42)\end{array}$ & $\begin{array}{l}2.84 \\
(1.75-4.62)\end{array}$ & $\begin{array}{l}1.85 \\
(1.31-2.63)\end{array}$ & $\begin{array}{l}0.98 \\
(0.54-1.79)\end{array}$ \\
\hline High & $\begin{array}{l}1.32 \\
(0.89-1.96)\end{array}$ & $\begin{array}{l}1.65 \\
(1.02-2.66)\end{array}$ & $\begin{array}{l}7.24 \\
(4.59-11.40)\end{array}$ & $\begin{array}{l}4.23 \\
(3.06-5.83)\end{array}$ & $\begin{array}{l}1.81 \\
(1.07-3.05)\end{array}$ \\
\hline \multicolumn{6}{|c|}{ Adjusted OR (95\% Cl) } \\
\hline Low & 1 & 1 & 1 & 1 & 1 \\
\hline Medium & $\begin{array}{l}0.74 \\
(0.46-1.21)\end{array}$ & $\begin{array}{l}1.33 \\
(0.76-2.34)\end{array}$ & $\begin{array}{l}2.16 \\
(1.29-3.65)\end{array}$ & $\begin{array}{l}1.96 \\
(1.34-2.87)\end{array}$ & $\begin{array}{l}1.05 \\
(0.54-2.02)\end{array}$ \\
\hline High & $\begin{array}{l}1.27 \\
(0.81-2.00)\end{array}$ & $\begin{array}{l}1.51 \\
(0.87-2.60)\end{array}$ & $\begin{array}{l}5.64 \\
(3.47-9.27)\end{array}$ & $\begin{array}{l}6.33 \\
(4.25-9.42)\end{array}$ & $\begin{array}{l}1.93 \\
(1.04-3.55)\end{array}$ \\
\hline
\end{tabular}

Adjusted for age, gender, education level, job autonomy and occupational position

$\begin{array}{llllll}\text { Low } & 1 & 1 & 1 & 1 & 1 \\ \text { Medium } & 0.68 & 1.20 & 1.98 & 1.53 & 1.06 \\ & (0.39-1.13) & (0.62-2.14) & (1.08-3.42) & (1.01-2.32) & (0.48-2.31) \\ \text { High } & 0.99 & 1.07 & 4.18 & 4.41 & 1.24 \\ & (0.62-1.57) & (0.61-1.88) & (2.48-7.04) & (2.85-6.80) & (0.62-2.49)\end{array}$

Adjusted for age, gender, education level, job autonomy and occupational position and distress symptoms reported at 2013 
Table 3 Crude and adjusted ORs ( $95 \% \mathrm{Cls}$ ) of external workload group (low, medium, high) (2013-2016) on physical and psychological well-being

\begin{tabular}{|c|c|c|c|c|c|}
\hline & Anxiety & Depression & $\begin{array}{l}\text { Psychological } \\
\text { fatigue }\end{array}$ & $\begin{array}{l}\text { Physical } \\
\text { fatigue }\end{array}$ & $\begin{array}{l}\text { Sleep } \\
\text { problems }\end{array}$ \\
\hline \multicolumn{6}{|c|}{ Crude OR $(95 \% \mathrm{Cl})$} \\
\hline Low & 1 & 1 & 1 & 1 & 1 \\
\hline Medium & $\begin{array}{l}0.85 \\
(.57-1.26)\end{array}$ & $\begin{array}{l}0.81 \\
(.522-1.28)\end{array}$ & $\begin{array}{l}1.59 \\
(1.78-1.51)\end{array}$ & $\begin{array}{l}1.00 \\
(.75-1.33)\end{array}$ & $\begin{array}{l}1.17 \\
(0.69-1.99)\end{array}$ \\
\hline High & $\begin{array}{l}0.91 \\
(0.65-1.28)\end{array}$ & $\begin{array}{l}0.85 \\
(0.58-1.24)\end{array}$ & $\begin{array}{l}1.67 \\
(1.26-2.22)\end{array}$ & $\begin{array}{l}1.10 \\
(0.86-1.40)\end{array}$ & $\begin{array}{l}0.91 \\
(0.60-1.37)\end{array}$ \\
\hline \multicolumn{6}{|c|}{ Adjusted OR (95\% Cl) } \\
\hline Low & 1 & 1 & 1 & 1 & 1 \\
\hline Medium & $\begin{array}{l}1.21 \\
(0.77-1.88)\end{array}$ & $\begin{array}{l}1.01 \\
(0.62-1.64)\end{array}$ & $\begin{array}{l}1.21 \\
(0.85-1.73)\end{array}$ & $\begin{array}{l}1.16 \\
(0.85-1.59)\end{array}$ & $\begin{array}{l}1.37 \\
(0.77-2.44)\end{array}$ \\
\hline High & $\begin{array}{l}1.12 \\
(0.75-1.66)\end{array}$ & $\begin{array}{l}1.09 \\
(0.69-1.71)\end{array}$ & $\begin{array}{l}1.77 \\
(1.26-2.50)\end{array}$ & $\begin{array}{l}1.47 \\
(1.09-1.98)\end{array}$ & $\begin{array}{l}1.23 \\
(0.74-2.04)\end{array}$ \\
\hline \multicolumn{6}{|c|}{ Adjusted for age, gender, education level, job autonomy and occupational position } \\
\hline Low & 1 & 1 & 1 & 1 & 1 \\
\hline Medium & $\begin{array}{l}0.98 \\
(0.62-1.54)\end{array}$ & $\begin{array}{l}0.91 \\
(0.55-1.51)\end{array}$ & $\begin{array}{l}1.45 \\
(0.95-2.19)\end{array}$ & $\begin{array}{l}1.12 \\
(0.79-1.61)\end{array}$ & $\begin{array}{l}0.86 \\
(0.45-1.63)\end{array}$ \\
\hline High & $\begin{array}{l}1.03 \\
(0.68-1.59)\end{array}$ & $\begin{array}{l}1.01 \\
(0.63-1.61)\end{array}$ & $\begin{array}{l}1.46 \\
(1.00-2.14)\end{array}$ & $\begin{array}{l}1.36 \\
(0.98-1.90)\end{array}$ & $\begin{array}{l}1.17 \\
(0.66-2.06)\end{array}$ \\
\hline
\end{tabular}

Adjusted for age, gender, education level, job autonomy and occupational position and distress symptoms reported at 2013

symptoms associated with medium and high internal workload, respectively.

Table 3 presents the crude and adjusted ORs for external recovery. Surprisingly, we found no significant dose-response effect of medium exposure for external workload on any of the distress symptoms. However, there was a dose-response effect for high external workload on psychological fatigue, $\mathrm{OR}=1.65$ (adjusted $\mathrm{OR}=1.77$ ). Thus, chronic exposure to high external workload was associated with increased risk of reporting psychological fatigue. The only other distress symptom associated with high external workload was physical fatigue, but only once the analysis was adjusted for the covariates $(\mathrm{OR}=1.47)$.

Online supplementary table S4 summarises the crude and adjusted ORs for external workload based on the data from the averaged measure of workload between 2013 and 2016, and distress symptoms. For psychological fatigue, the ORs for the medium exposure group was 1.40 and $1.58(\mathrm{OR}=1.41$ after adjusting for age, gender, education level, job autonomy, occupational position and distress symptoms reported at 2013). Physical fatigue was the only other distress symptom associated with medium $(\mathrm{OR}=1.24)$ and high $(\mathrm{OR}=1.32)$ external workload, but only once the analysis was for adjusted for age, gender, education level, job autonomy and occupational position.

\section{DISCUSSION}

The aim of the present study was to explore the health-related factors within individuals who persistently fail to take recovery opportunities, during or after work. Our analysis revealed that high internal workload-defined as habitually having too much work to do during working hours-was associated with increased psychological fatigue, physical fatigue and sleep problems. Specifically, individuals who regularly experienced high internal workload were found to be seven times more likely to report psychological fatigue, four times more likely to report physical fatigue and nearly twice as likely to report sleep problems, relative to those that did not. Interestingly, the association between internal workload and the distress symptoms remained after adjustments for the covariates including job autonomy and occupational position.

Conceivably, the greatest recovery occurs during our free/leisure time; however, technology has made it increasingly more difficult for workers to detach from work as the boundary between work and home is now more permeable. The ease of checking work emails, social media or various Twitter/news feeds, in addition to making and receiving phone calls, means that we rarely spend time simply being and relaxing. ${ }^{29}{ }^{30}$ Even during breaks within the working day, people check work-related emails. It is thus becoming more common for people to attend to work-related issues during their personal time ${ }^{29}$ and by doing so, ipso facto, this limits the available time to unwind and recover. Järvenpää and Lang ${ }^{31}$ introduced the notion of the 'Empowerment/Enslavement Paradox'. This highlights two contrasting perspectives concerning the influence of technology on well-being. The use of technology allows the worker more flexibility over how they manage their working and home life which could lead to feelings of satisfaction and control. ${ }^{32}$ Thus, the use of technology may be an insulating factor against high workload and stress and therefore empower individuals. Contrarily, the opposing view suggests that the availability of technology may encourage more work-related behaviour, thus limiting the time to relax. Technology therefore may actually decrease an individual's feeling of control ${ }^{33}$ and persistent use of technology for work could reduce health and well-being long term. ${ }^{34}$ Interestingly, there is empirical support for both perspectives and therefore the evidence remains inconclusive. ${ }^{18}$ In the present study, our findings lend support for the latter hypothesis in that external workload-defined as being electronically connected to work and being contactable about work outside normal working hours-was associated with increased psychological fatigued. Indeed, workers who reported high external workload were 1.67 times more likely to report psychological fatigue relative to those who did not.

The analysis see(online supplementary material) was recalculated using the average measure of workload between 2013 and 2016, which increased the sample size. Interestingly, even with an increased number of participants, the results were very similar, although with slightly lower ORs. Thus, the effect of workload appears stronger when individuals consistently report the same level of workload exposure overtime.

Several researchers have commented that there has been a relative lack of research examining internal recovery ${ }^{20} 21$ and interestingly within this study, lack of internal recovery, that is, high internal workload, was found to be more important in respect for distress symptom reporting that recovery that takes place at the end of the working day. Considering that workers spend approximately a third of their day working, this is an important finding, suggesting that workers who frequently experience a high workload (with the possibility of missing adequate breaks) are potentially putting their health at risk. Although there will be individual differences, ${ }^{36}$ there is a trend of working through lunch, and this trend needs to be reversed. Interestingly, a longitudinal study reported that the proportion of energy and macronutrients consumed at lunch time has decreased over a 17 year period and that perhaps this is due to people not stopping to have a proper lunch. ${ }^{37}$

There are several initiatives aimed to enhance recovery during work, such as lunchtime 'green exercise' programmes, ${ }^{38}$ but these may, to some extent, be dependent on the availability of 
green space. Perhaps the most obvious way to ensure that workers rest is to make breaks mandatory where possible. This could be achieved by a top-down managerial approach by enforcing a fixed work-rest schedule throughout the day. However, a bottom-up approach through educating the workforce is also needed. The notion of recovering from work during working hours seems to be counterintuitive and a contradiction in terms, but as recovery is a dynamic process, ${ }^{5}$ scheduling frequent breaks during the working day and encouraging recovery activities should reduce the likelihood of fatigue postwork. ${ }^{14} 1739$

\section{LIMITATIONS}

First, the data were collected within one country and therefore the results may not generalise to other countries. Second, although one of the strengths of this study was that the same individuals are followed-up over time, there was a substantial dropout of individuals between 2013 and 2016. While this may be expected to a degree, it should be noted that the difference was greater with regards to the education background of the respondents, with higher education being overrepresented. There was however no statistical difference in age or gender in those who participated in the 2016 survey and those who dropped out. Third, although we demonstrated that chronic internal workload was associated with increased postwork distress symptom reporting, we were unable to address the factors that inhibit or promote recovery in the present study. Indeed, there is a lack of evidence concerning the ideal rest break in terms of timing, length or activity and this would somewhat depend on the nature of the job and the individual. Another limitation relates to our definition of the word chronic. In this study, we define chronic workload, as those who reported the same experience of workload at two time points (low, medium and high), but in reality, workload may fluctuate over time. There are likely to be periods over the 3 years when workload is high, and other times when workload is lower. Due to the date collection methods of the survey, it was not possible to assess workload at other times during the 3 years.

To control for the possibility of reversed causality-it is possible that individuals with poorer well-being evaluate their workload higher-adjustment for reported distress symptoms at baseline was added in a third step on the analysis. While this weakened the association between workload and the outcome indicators, it may also have been an underestimation of the true effects of the association; it is likely that some participants reporting elevated distress may have had high workload preceding their enrolment on the study. Finally, this study used single-item measures, the use of which may be questioned. However, due to practicality constraints (eg, survey length, repeated sampling over time and sample size), a recent review concluded that single items can provide valid information. ${ }^{40}$ Notwithstanding these limitations, one of the strengths of this study was that it examined the chronic effects of workload on health and reported the findings of internal and external workload using the same distress measures. In addition, this was a population-based study and individuals were selected from a variety of occupation, therefore increasing representation of the findings. When compared to population studies, the prevalence of common mental health symptoms in specific occupational studies tends to be higher. ${ }^{41}$ This study also adds to the literature on the role of internal recovery and well-being.

\section{CONCLUSION}

Most people will find themselves occasionally skipping breaks and working during the evening in order to meet important deadlines or to complete work before they go on leave. In the short term, this is unlikely to have long-term health consequences. However, persistently being exposed to a high workload appears to be associated with increased risk of fatigue and sleep problems. This study was conducted over a period of 3 years, and further work is needed to establish the longer effects and whether habitually experienced fatigue develops into additional health problems over time.

What is already known on this subject

- The need for recovery from the demands of work has been associated with workers' detachment from work and well-being. Recovery from work can occur both during the working day, by way of rest breaks (ie, internal recovery), and outside or work, during leisure time, by not working in the evening (ie, external recovery). Recovery can be compromised when workload is high. It remains unclear how the experience of exposure to persistent high workload over time affects health and well-being, and whether similar effects are found for internal and external workload. Most research has focused on external workload and there is a lack of studies that have examined the effects of workload longitudinally.

\section{What does this study adds}

This study showed that chronic workload both during the day and evening is associated with increased risk of reporting psychological fatigue, physical fatigue and sleep problems. Interestingly, the effects on health are particularly salient when recovery opportunities are not taken during the working day. These results highlight the importance of workers needing to take time away from the demands of work by taking regular recovery breaks throughout the day as a prerequisite for maintaining health and well-being.

Contributors MC accomplished the analyses and wrote the main parts of the manuscript. LWR wrote part of the manuscript and added intellectual input. DA assisted with making the data from the public data set to apply for this study.

Funding The authors have not declared a specific grant for this research from any funding agency in the public, commercial or not-for-profit sectors.

\section{Competing interests None declared.}

\section{Patient consent for publication Not required.}

Provenance and peer review Not commissioned; externally peer reviewed.

Data availability statement Data are available in a public, open-access repository.

Open access This is an open access article distributed in accordance with the Creative Commons Attribution Non Commercial (CC BY-NC 4.0) license, which permits others to distribute, remix, adapt, build upon this work non-commercially, and license their derivative works on different terms, provided the original work is properly cited, appropriate credit is given, any changes made indicated, and the use is noncommercial. See: http://creativecommons.org/licenses/by-nc/4.0/.

\section{ORCID iDs}

Mark Cropley http://orcid.org/0000-0002-8483-1797

Leif W Rydstedt http://orcid.org/0000-0001-7293-349X

\section{REFERENCES}

1 Hobfoll SE. Conservation of resources: a new attempt at conceptualizing stress. Am Psychol 1989;44:513-24. 
2 Gorgievski M, Hobfoll S. Work can burn us out or fire us up: conservation of resources in burnout and engagement. In: Halbesleben J, ed. Handbook of stress and burnout in health care. New York: Nova Science Publishers, 2008: 7-22.

3 Meijman TF, Mulder G. Psychological aspects of workload. In: Drenth PJD, Thierry H, eds. Handbook of work and organizational psychology: vol. 2. Work psychology. Hove, UK: Psychology Press, 1998: 5-33.

4 Sluiter JK, van der Beek AJ, Frings-Dresen MH. The influence of work characteristics on the need for recovery and experienced health: a study on coach drivers. Ergonomics 1999:42:573-83.

5 Zijlstra FRH, Cropley M, Rydstedt LW. From recovery to regulation: an attempt to reconceptualize 'recovery from work'. Stress Health 2014;30:244-52.

6 Geurts SA, Sonnentag S. Recovery as explanatory mechanism in the relation between acute stress reactions and chronic health impairment. Scand J Work Environ Health 2006;32:482-92.

7 Kühnel J, Zacher H, De Bloom J, et al. Take a break! Benefits of sleep and short breaks for daily work engagement. EJWOP 2017;26:481-91.

8 Demerouti E, Bakker AB, Sonnentag S, et al. Work-related flow and energy at work and at home: a study on the role of daily recovery. JOB 2012;33:276-95.

9 Fritz C, Lam CF, Spreitzer GM. It's the little things that matter: an examination of knowledge workers' energy management. Acad Manage Perspect 2011;25:28-39.

10 Lombardi DA, Jin K, Courtney TK, et al. The effects of rest breaks, work shift start time, and sleep on the onset of severe injury among workers in the People's Republic of China. Scand I Work Environ Health 2014;40:146-55.

11 Kim S, Park Y, Headrick L. Daily micro-breaks and job performance: general work engagement as a cross-level moderator daily micro-breaks and job performance: general work engagement as a cross-level moderator. JAP 2018;107:772-86. .

12 Sianoja M, Syrek CJ, de Bloom J, et al. Enhancing daily well-being at work through lunchtime park walks and relaxation exercises: recovery experiences as mediators. JOHP 2018;23:428-42.

13 Sianoja M, Kinnunen U, de Bloom J, et al. Recovery during lunch breaks: testing long-term relations with energy levels at work. Scand I Work Organizational Psychol 2016;1:1-12.

14 Trougakos JP, Hideg I, Cheng BH, et al. Lunch breaks unpacked: the role of autonomy as a moderator of recovery during lunch. Acad Manage J 2014;57:405-21.

15 Sianoja M, Kinnunen U, de Bloom J, et al. Insufficient recovery from job stress as a risk factor for poor health and well-being. In: Hopkins CR, ed. Job stress: risk factors, health effects and coping strategies. USA: Nova Science Publishers, 2015: 27-47.

16 Hunter EM, Wu C. Give me a better break: choosing workday break activities to maximize resource recovery. JAP 2016;101:302-11.

17 Tucker $P$. The impact of rest breaks upon accident risk, fatigue and performance: a review. Work Stress 2003;17:123-37.

18 Schlachter S, Mcdowall A, Cropley M, et al. Voluntary work-related technology use during non-work time: a narrative synthesis of empirical research and research Agenda. Int J Manag Rev 2017.

19 McEwen BS. Stress, adaptation, and disease: allostasis and allostatic load. Ann N Y Acad Sci 1998:840:33-44

20 von Dreden C, Binnewies C. Choose your lunch companion wisely: the relationships between lunch break companionship, psychological detachment, and daily vigour. EJWOP 2017;26:356-72.

21 Sonnentag S, Fritz C. Recovery from job stress: the stressor-detachment model as an integrative framework. JOB 2015;36:72-103.

22 Karasek R, Brisson C, Kawakami N, et al. The Job Content Questionnaire (JCQ): an instrument for internationally comparative assessments of psychosocial job characteristics. J Occup Health Psychol 1988;3:322-55.
23 Demerouti $E$, Bakker AB, Geurts SAE, et al. Daily recovery from work-related effort during non-work time. Res Occup Stress Well Being 2009;7:85-123.

24 Geurt SAE, Sonnentag S. Recovery as an explanatory mechanism in the relation between acute stress reactions and chronic health impairment. Scand J Work Environ Health 2006;32:482-92.

25 Gustavsson K, Lindfors P, Aronsson G, et al. Relationships between self-rating of recovery from work and morning salivary cortisol. J Occup Health 2008;50:24-30.

26 van Veldhoven MJPM, Sluiter JK. Work-related recovery opportunities: testing scale properties and validity in relation to health. Int Arch Occup Environ Health 2009;82:1065.

27 Statistisk Sentrabyrå. Norsk standard for utdanningsgruppering, revider 2000 (Norwegian standard for educational grouping. Revised 2000). Olso, NO: Statistics Norway, 2001.

28 Statistisk S. Standard for yrkesklassifisering (STYRK 08). (Standard for Occupational Classification). Oslo, NO: Statistics Norway, 201117

29 Bureau of Labor Statistics. News release: American time use survey-2016 results. Available https://www.bls.gov/news.release/pdf/atus.pdf (accessed 2017, Jun 27).

30 Cropley M, Plans D, Morelli D, et al. The association between work-related rumination and heart rate variability: a field study. Front Hum Neurosci 2017;11.

31 Järvenpää SL, Lang KR. Managing the paradoxes of mobile technology. Inf Syst Manage 2005;22:7-23.

32 Hill EJ, Erickson JJ, Holmes EK, et al. Workplace flexibility, work hours, and work: life conflict: finding an extra day or two. J Family Psychol 2010;24:349-58.

33 Besseyre Des Horts CH, Dery K, MacCormick J. Paradoxical consequences of the use of blackberrys: an application of the job demand: control-support model. In: Kelliher C, Richardson J, eds. New ways of organizing work: developments, perspectives and experiences. London: Routledge, 2012: 16-29.

34 Day A, Scott N, Kelloway EK. Information and communicaAtion technology: implications for job stress and employee well-being. In: Perrewe PL, Ganster DC, eds. New developments in theoretical and conceptual approaches to job stress. Bingley: Emerald 2010: 317-50.

35 Nixon AE, Spector PE. The impact of technology on employee stress, health, and wellbeing. In: Coovert MD, Thompson LF, eds. The psychology of workplace technology. New York, NY: Routledge, 2014: 238-60.

36 Sonnentag S, Venz L, Casper A. Advances in recovery research: what have we learned? What should be done next? JOHP 2017;22:365-80.

37 Almoosawi S, Winter J, Prynne CJ, et al. Daily profiles of energy and nutrient intakes: are eating profiles changing over time? Eur J Clin Nutr 2012;66:67886.

38 Brown DK, Barton JL, Pretty J, et al. Walks4Work: assessing the role of the natural environment in a workplace physical activity intervention. Scand J Work Environ Health 2014:40:390-9.

39 Trougakos JP, Hideg I. The role of within-day work breaks. In: Sonnentag S, Perrewé PL, Ganster DC, eds. Current perspectives on job-stress recovery research in occupational stress and well being. Bingley, UK: Emerald Group Publishing Limited, 2009: 37-84.

40 Fisher GG, Matthews RA, Gibbons AM. Developing and investigating the use of single-item measures in organizational research. J Occup Health Psychol 2016:21:3.

41 Goodwin L, Ben-Zion I, Fear NT, et al. Are reports of psychological stress higher in occupational studies? A systematic review across occupational and population based studies. PLoS One 2013;8:e78693. 